in the first stage after rupture of the membranes and that early dilatation of the cervix by means of Barnes' dilators might have averted the damage to the cervix which was the sole and direct cause of the fatal result.

Curzon-street, Mayfair, W.

\section{SOME POINTS OF PRACTICAL IMPORT- ANCE IN THE USE OF CURVED SKIN INCISIONS.}

BY PEYTON T. B. BEALE, F.R.C.S.ENG.,

SURGEON TO OUT-PATIENTS, GREAT NORTHERN CENTRAL HOSPITAL; DEMONSTHATOR OF PHYSIOLOGY IN KING'S COLLEGE.

ON reading the descriptions of operations in the text-books and journals one is struck by the apparent indifference displayed as to the form of skin incision to be employed, whether curved, straight \&c., and I have been much interested in watching the nltimate result of any particular operation performed by various surgeons under practically the same conditions and by the use of different forms of skin incisions. I hope to be able in this paper to investigate the reasons for the adoption of any one special form of incision and to demonstrate the particular advantages of curved incisions wherever these are possible. It used frequently to be said that as small an incision should be made as is compatible with the removal of the disease or the proper exposure of the part to be operated upon, because the smaller the wound the less is the amount of shock, the quicker is the process of repair and the less chance there is of the entrance of septic or other organisms from without. But it must be admitted that the tendency is generally to make too small an incision at first, which leads to great disturbance of the edges of the wound and of the parts beneath in order to give sufficient room for the completion of the operation, and only too often, as the operation proceeds, the wound has to be enlarged, valuable time has been spent in trying to reach the parts beneath and unnecessary bruising of the tissues has resulted. In making a curved incision, of course, a greater amount of skin is divided, but there is no evidence to show that a few inches one way or the other increases the shock or severity of the operation, and in these days the entrance of organisms can be prevented by the proper cleansing of the skin in the first place, by irrigation during operation and by the use of aseptic and antiseptic dressings afterwards. There are some situations where a curved incision is now almost universally used-for example, the scalp, since it gives rise to less hæmorrhage, the vessels divided being smaller and tending to retract more than when a straight incision is employed. Moreover, the bone beneath is more fully and more quickly exposed for subsequent treatment. This form of incision is also applicable, for the former reason, to other situations where one or two fairly large arteries rapidly break up into smaller branches. I will give a very few examples from amongst the many situations where, for these and other reasons, a curved incision is preferable to a straight one. In dissecting out varicose veins in the thigh or leg I bave always made a curved incision, and when excising a long portion of vein, in those cases where the proceeding is essential, one shaped thus, the position of the vein being indicated by the dotted line. The convex flaps of skin and subcutaneous tissue are dissected up to their bases and then a piece of thick silk is threaded through the convex margin. In this way the flap can be held to one side and by traction the hæmorrhage at its edge can be practically stopped. The vein is also fully exposed and it and most of its branches can be easily ligatured and removed. When a straight incision has been used for this operation it is often observed that primary union does not occur along the whole of the wound. This I believe to be very often due to the edges of the skin having been pulled about with forceps and continually rubbed and irritated during the operation by the use of blunt hooks or retractors ; Professor Rose has advised the use of the fingers only to hold up the edges of the skin. If a curved incision be made and the flap be held back as described the edges of the skin need not be even touched until they are sutured together, and I have been very much struck with the rapid and perfect primary union which has occurred and with the freedom from pain afterwards due to the cicatrix being well away from the site of the vein. In the operation for wiring fractured patella or for excising the bursa in front of the ligamentum patellæ a curved incision, convex downwards, its apex being just above the tubercle of the tibia, is most satisfactory, as the flap so formed can be lifted up and fixed with a stitch and the operation proceeded with; the resulting scar is thus well below the knee and escapes pressure subsequently. In removing tubercular glands where the skin is slightly or not at all affected it appears to me most useful to dissect up a flap of skin, for the skin incision then is quite away from the disease and there is little risk of the edges becoming infected, as so often happens, and if a drainagetube is to be used it can be placed with advantage at one or other extremity of the incision. Again, in some cases of acute abscess it is most valuable to be able to make the skin incision in healthy skin around the abscess and evacuate

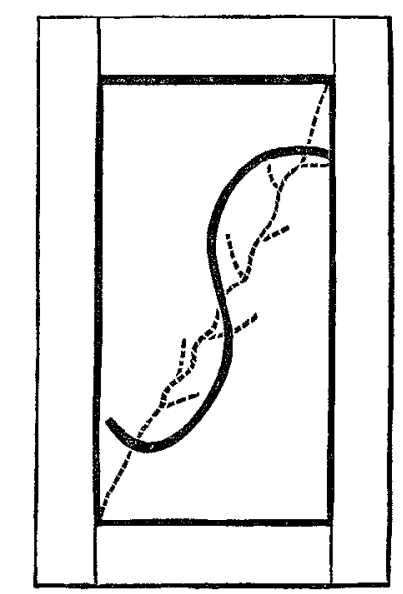

the pus through it. I think it is very doubtful whether the in flamed skin ought to be incised in these cases, for skin in that condition is not well able to resist the entrance of organisms, and, as a matter of fact, does often become infected, thus preventing primary union and often leading to a little sloughing of the edges and further trouble.

I will now give a few reasons for preferring a curved to a straight incision wherever the former is practicable: 1 . It heals more rapidly and for these reasons : there is really only one edge of the wound, that belonging to the flap, that is movable, the other edge being still adherent to the subjacent tissue ; moreover, the flap having been stitched to the neigh. bouring skin or held well away from the seat of operation both edges of the wound are quite uninjured by the time the sutures are inserted. 2. The resulting scar is smaller, though this is only of importance in certain parts, for the skin may be incised obliquely in making a curved incision, so that the epidermis on the edge of the flap is slightly in advance of the true skin. 3. It fully exposes the part to be operated upon, assuming that the base of the flap is twice o: three times its length, and gives the operator plenty of room in which to work. 4. Suturing the edges is easier than in the case of a straight incision, especially if the skin be pricked in one or two situations exactly opposite to one another before the incision is made, and often the curved wound is adapted to the shape of the part better than a straight one. 5. The resulting cicatrix is not over the seat of operation. 6. Drainage is often most perfect by inserting a tube through an incision in the base or some part of the flap, thus giving no hindrance to the primary union of the incision and preventing any possible discharge from infecting the edges. 7. Incision through inflamed or diseased skin may be avoided and yet the disease be easily reached. 8. There need be no tension on the edges of the wound, as a flap of skin is, so to speak, loose, and if there is fear of tension a thick silk suture may be passed through the base or some part of the flap and ont again, and then through the skin on the other side of the incision and there fixed, thus avoiding a long suture beneath either edge of the wound. I think that the form of skin incision, its subsequent result to the patient, and its immediate results to the surgeon during the progress of an operation are matters too often neglected and not sufficiently considered before the operation is undertaken, and I feel sure that there are many points of interest connected with the subject.

Grosvenor.street, W. 


\section{CARCINOMA RECTI; RIGHT INGUINAL COLOTOMY.}

BY ALFRED COOPER, F.R.C.S. ENG. \&c.,

SENIOR SURGEON TO ST. MARK'S HOSPITAL FOR FISTULA AND OTHER DISEASES OF THE RECTUM.

A B00KBINDER aged fifty-six was admitted into St. Mark's Hospital for Fistula and other Diseases of the Rectum on Nov. 12th, 1892, suffering from malignant disease of the rectum. There was no history of cancer or rectal disease in the patient's family. He had enjoyed good health until four months before admission. $\mathrm{He}$ had had measles and whooping-cough when a child, but no severe illness since. He had not suffered from any previous rectal trouble, such as hæmorrhoids or fistula. The bowels had been regular all his life. There was no history of previous abdominal inflammation. About four months ago the patient noticed for the first time a constant desire to evacuate the contents of his rectum, this being the first symptom of rectal discomfort that he complained of. Since then the motions had always been very relaxed; he had not had a formed motion for the previous sixteen weeks. Two months after the first onset of these symptoms he noticed when at stool that his motion was streaked with blood of a bright-red colour. Since then he had continually passed blood when his bowels had acted, but not to any great extent. He had felt little or no pain in the rectum, the only discomfort being the constant desire to go to stool, and even when his bowels acted this feeling did not pass off. He occasionally complained of pains shooting down both thighs. As he was continually losing blood and could not obtain any relief from the constant desire to defecate he was advised to attend St. Mark's Hospital, where he was found to be suffering from carcinoma. On admission the heart and lungs were normal, and the urine was acid, clear, of sp. gr. 1020, and containing no albumen. On rectal examination adranced malignant disease was found, starting two inches above the anus. Its upper limit could not be determined as the finger could not reach above it. The growth had already invaded the surrounding tissues. On Nov. 22nd, the patient having been placed under the influence of chloroform, I made the usual incision for left inguinal colotomy, my colleague, Mr. Swinford Edwards, assisting me. Having opened the peritoneal cavity, a scarch was made for the sigmoid colon, but in vain, nor were Messrs. Goodsall and Edwards more fortunate in their attempts. There was clearly a malposition of the gut, so on Mr. Goodsall's recommendation it was determined to close the wound and to perform the operation on the right side with a view of opening the cæcum, or perhaps even the sigmoid, for it has been known to take up this position when it has failed to occupy its own. This having been done, the gut was found lying over the cæcum and firmly fixed there, so that it could not be drawn out of the wound. This being the case, the mesenteric suture was omitted, the bowel being simply stitched to the united skin and peritoneal edges by several sutures. The patient was then ordered to have a pint of milk during the next twenty-four hours.

Nov. 23rd. - The patient slept fairly well during the night; he has had no sickness; he took his milk well. The temperature is $974^{\circ}$; the pulse is 68 , regular. He states that he has a feeling of discomfort all over the abdomen, but not actual pain ; he seems very bright and in good spirits. Evening: $\mathrm{He}$ has had a very good day. The temperature is now $98.8^{\circ}$; the abdominal discomfort is much less.

24th.-He passed a very good night. He has had a pint of milk and half a pint of beef-tea within the last twenty-four hours; there has been no sickness or pain. The temperature is $982^{\circ}$; the pulse is 64 , regular. The dressings over the right wound were removed by the house surgeon, Mr. Ryall, and, the gut being distended, he incised it with scissors, where upon fluid fæces and a quantity of gas escaped. Evening The bowels have freely acted through the colotomy wound, the fæces that passed being still fluid. The patient has had a very good day. The temperature is $984^{\circ}$.

25th.-He slept well during the night ; there is no pain or sickness. The bowels have been freely relieved through the colotomy wound, the fæces being still liquid. The temperature is $984^{\circ}$; pulse 60 .

The patient made daily progress towards recovery without a bad symptom of any kind, the sutures being removed from the right colotomy wound on Nov. 27 th, and from the left, which had healed, on Nov. 29th. On Dec. 8th a right inguinal colotomy truss was applied and he was discharged from the hospital much relieved on Dec. 10th, eighteen days after the operation.

Memarks. - It has been thought worth while to record this case as an example of a somewhat rare condition occasionally met with in performing inguinal colotomy and also as showing what seems to be the best way of dealing with it. On finding the large intestine on the right side it was easy, of course, to recognise it, but less so to determine whether it was the mal-placed sigmoid or the cæcum. Time alone solved this question. Although the evacuations were always fluid when in hospital, looking as though it was the crecum which had been opened, they soon became more firm and formed, which would not have been the case had it been the beginning of the large intestine. Mr. Swinford Edwards saw the patient last on Jan. 4th, 1893, when he appeared very comfortable, though he complained a little of his rectum and of the annoyance caused by a small amount of fæces passing that way. This was unavoidable, because, as mentioned above, the gut being tightly held down, it was impossible to form a spur by means of a deep or mesenteric suture, a proceeding most necessary to ensure the full benefits of the operation. He was passing wellformed and solid motions through the artificial anus. It should be mentioned that excision of the rectum in this case was contraindicated, not only on account of the height to which the growth extended, but more especially seeing that the disease had already to some extent involved the surrounding structures.

Henrietta-street, W.

\section{ICE IN THE TREATMENT OF ACUTE PNEUMONIA.}

A COLLECTIVE REPORT.

BY THOMAS J. MAYS, M.D.,

PROFESSOR OF DISEASES OF THE CHEST IN THE PHILA DELPHIA POLY. CLINIC, VISITING PHYSICIAN TO THE RUSH HOSPITAL FOR
CONSUMPTIVES ETC.

WHATEVER its nature may be, it is quite certain that no other disease has elicited a greater number of conflicting opinions concerning its treatment than has croupous pneu. monia. Forty years ago bleeding and blistering were regarded as its specifics; but these are now, and for the last twenty years have been, scarcely thought of in this connexion. In the meantime hot poultices, aconite, veratrum viride, digitalis, quinine \&c., have taken their places, yet it is not too much to say that they have all led to disappointment and come to grief in the retort of clinical experience, and that finally the profession has gravitated to the conviction that the disease is self limited in duration, and that hence all efforts to control its course are fruitless, if not actually harmful. To be thus compelled to stand before a disease and acknowledge one's helplessness and impotency is, to say the least, an un. enviable position, but I must confess that until I became familiar with the value of local cold applications in this disease I was in hearty accord with this idea. Since then I may say that I am able to approach a case of pneumonia with a greater degree of assurance-not with the feeling, however, that we possess a specific, but with the confidence that here is an agent with which we are able to impress and circumvent the severity of the pneumonic process. I believe that cold properly applied will affect the death-rate of pneamonia as profoundly as it has affected that of typhoid fever, and, although I do not expect a rapid introduction of this measure, on account of a deep-rooted prejudice which exists against the use of cold in almost all internal diseases, I trust that the evidence which is herewith submittea will serve to commend it to the serious attention of the profession. Under the titles, "Can Croupous Pneumonia be Abater ?" and "Ice in the Treatment of Croupous Pneumonia," I contributed two papers to the Medical Ners of Sept. 24th, 1892, and Jan. 21st, 1893, respectively, in which are related three cases of pneumonia which were treated principally with applications of ice to the chest ; and since the appearance of the first paper I instituted a collective investigation on a small scale by sending a number of circulars ${ }^{2}$ to various

I Similar circulars will be cheerfully sent by mo to ang one who may apply for them. 